\title{
Metaphor through the Lens of Clinical Medicine: The Case of Specialty-Specific Signs
}

\author{
Svetlana Margaryan \\ Yerevan Brusov State University of Languages and Social Sciences \\ Alina Petrosyan \\ Mkhitar Heratsi Yerevan State Medical University
}

\begin{abstract}
The present paper aims at discussing certain metaphors which name diseases resembling specialty-specific signs manifested in different occupations. An attempt is made towards showcasing the cognitive value that metaphor entails when used in a clinical setting to verbalize different diseases. Stedman's Medical Dictionary currently the most content-rich medical dictionary - has served a major reference point for the analysis of specialty-specific metaphors in Medicine.
\end{abstract}

Key words: metaphor, medicine, specialty-specific signs, clinical practice, medical agenda, chemical, physical and biological agents.

\section{Introduction}

In different periods of time the world has witnessed key advancements in industry and technology which have in turn led to the emergence of new fields of specializations in order to keep pace with the ever-changing reality. However, this has also given rise to new forms of diseases which have been associated with the activities or workings conducted within these specialty fields or occupations. These health conditions which manifest specialty-specific signs have also been observed in humans not exposed to particular working conditions. In furtherance, the study of targeted medical literature has revealed that such health conditions can be verbalized through metaphors which make reference to specialty-specific signs. In other words, the field of specialty-specific signs serves a useful source in borrowing the needed term to name a particular health condition in the target domain. These borrowed terms better communicate the nature and specificities of the disease.

As to the application of metaphor for scientific purposes, it should be stated, that generally there are two strands of debate over the usage of metaphor in science, one of which is organized around the conceptual theory of metaphor and 
claims that metaphor is indispensable in scientific thought and understanding (Lakoff and Johnson 2003; Richards 1936). The other strand is around the philosophical concerns regarding metaphor considering the latter as an instrument in the art of rhetoric (Vickers 1970; Locke 2007). This paper embraces the conceptual approach and showcases the cognitive value of metaphor from the clinical perspective and medical rationality coupled with succinct summary of some of the major claims made by the school of conceptual theory.

\section{An Outline of Conceptual Approach to Metaphor}

Back in 1936 A. Richards was the first to present the cognitive theory of metaphor and further claim that metaphor should be regarded as a constituent component of language. In particular, Richards stated the following in "The Philosophy of Rhetoric" (1936:92), "Even in the rigid language of the settled sciences we do not eliminate or prevent it [i.e. metaphor] without great difficulty. In the semi-technicalised subjects, in aesthetics, politics, sociology, ethics, psychology, theory of language and so on, our constant chief difficulty is to discover how we are using it and how our supposedly fixed words are shifting their senses. In philosophy, above all, we can take no step safely without an unrelaxing awareness of the metaphors we, and our audience, may be employing; and though we may pretend to eschew them, we can attempt to do so only by detecting them. And this is the more true, the more severe and abstract the philosophy is. As it grows more abstract we think increasingly by means of metaphors that we profess not to be relying on."

According to Lakoff and Johnson (2003:4), metaphor “... is pervasive in everyday life, not just in language but in thought and action. Our ordinary conceptual system, in terms of which we both think and act, is fundamentally metaphorical in nature." The authors make an important claim in "Metaphors We Live By" (2003) by arguing that metaphor forms a central component of the human cognitive system. Another claim on metaphor by Gibbs (1994:122) states that metaphors "not only serve as the foundation for much everyday thinking", but also "continue scholarly theory and practice in a variety of disciplines."

\section{Metaphors Doctors Act by}

Doctors and clinicians follow different agendas in their routine therapeutic and clinical practice. They may be engaged in taking histories, treating diseases, examining and running patients, diagnosing disorders and pathologies and perform 
other healthcare activities as deemed necessary in a medical setting. Whatever the pattern of agenda, they communicate their ideas and conceptions of a particular clinical condition through various linguistic means, and the usage of metaphors appears to be central in such activities. Gerald Holton, Professor of Physics and Professor of the History of Science at Harvard University, states that "in the work of the active scientist there are not merely occasions for using metaphor, but necessities for doing so [...] the necessity built into the process of scientific rationality itself" (Holton 1998:236). Meanwhile, Anatole Broyard, American writer and literary critic, claims that "Metaphors may be as necessary to illness as they are to literature. [...] At the very least, they are a relief from medical terminology" (Broyard 1992:18). Apparently, metaphors help to transfer the intended idea and the complex nature of a phenomenon effectively and in a timeefficient manner. In addition, metaphors allow fulfilling certain goals in a clinical environment: doctors may use a metaphor to make a differential diagnosis (woolsorter's disease, baker's eczema, cobbler's chest) based on findings of radiological imaging or laboratory examination; make the clinical picture easy for understanding (ballerina pose, clown nose, obstetrician's hand) instead of using long and complex definitions, and most importantly, save time which is very precious in everyday clinical practice.

As to specialty-specific signs, usage of metaphor in such cases is also conditioned by the sociocultural aspect of perception of these health conditions. According to Paul Unschuld (1998:23), "The ideas of a nature of a healthy organism, or illness, and of appropriate therapeutic interventions that develop in medical systems $[\ldots]$ are highly reflective of the social and physical environment of the thinkers who developed these systems. Systems of medical ideas are, therefore, metaphors in themselves, revealing at least as much of the world where their authors lived, or would have preferred to live, as of what they tried to explain." Physicians are not isolated from the society, environment, culture, technology and many other factors which play a central role in shaping their understanding and interpretation of different phenomena, their experience and also background and professional knowledge. Specifically in the case of diseases by target organ systems activated through various infections and agents, physicians resort to metaphors in order to clearly verbalize the underlying cause of the disease since treatment or prevention can (in the majority of cases) be achieved if the cause or agent of the disease is clearly identified and known. Consequently, this will allow for an accurate diagnosis followed by a targeted route of treatment or 
selection of prevention options. Hence, in this case it is through metaphor that doctors highlight the agent of the disease, thus establishing a precise diagnosis and selecting certain option of treatment.

\section{Specialty-Specific Signs as Metaphors for Diseases}

Exposure to different risk factors which arise from the occupation or professional activity may lead to numerous health conditions and disorders. Quite frequently these diseases manifest specific signs which are then attributed to the same conditions seen in other humans who are not engaged in that particular activity giving rise to these abnormalities. In such cases the association between two different conceptions from different realms of knowledge plays a major role in shaping the requisite term to name the disease. Consequently, health conditions with resemblance to specialty-specific signs are often verbalized through metaphors. Such signs may arise from inhaling certain chemical, physical and biological agents and dusts as well as from performing certain type of activities which cause skin diseases and musculoskeletal disorders. Hence, this paper is an attempt to make a selection from the group of such distinctions and study those diseases which are named through metaphors based on association of resemblance of a specialty-specific sign.

As Sisakyan states, inhalation of airborne and mineral dusts can cause lung diseases, in particular (Sisakyan, Ayvazyan 2011). These dusts are later deposited in the lungs thus affecting them and causing severe damage. One of such conditions is metaphorically named woolsorter's disease, which is a pulmonary infection acquired by inhalation of dust containing "Bacillus anthracis." Typical signs include initial chill followed by pain in the back and legs, rapid respiration, cough, fever, rapid pulse, and extreme cardiovascular collapse. This disease is also known by series of synonyms such as ragpicker's disease, rag sorters' disease or woolsorter's pneumonia. Similar diseases are flax-dresser's disease, which is a chronic obstructive pulmonary condition caused by inhalation of particles of unprocessed flax; and weaver's cough - the term for cough, dyspnea, and sense of constriction of the chest, caused by mildewed yarn.

Quite interesting appears to be the case of legionnaire's disease where the etiology of the disease and the etymology of the metaphoric naming are interrelated. According to various research sources and scientific data (World Health Organization; Mayo Clinic, Diseases and Conditions; Skinner1949) this is a severe form of bacterial pneumonia or a serious lung inflammation which is usually 
caused by infection. The agent of this infection is the bacterium widely known as "Legionella pneumophila" ("pneumophila" meaning "lung-loving" from Greek pneumōn (lung), and phila (friendship) or philos (dear) denoting "fondness, especially an abnormal love for a specified thing" (Oxford Dictionaries) which was first identified after an outbreak of severe pneumonia in 1976 among participants of convention of the American Legion (U.S. military veterans' organisation) in Philadelphia (World Health Organization). According to key facts provided by the WHO, inhalation of contaminated aerosols through air conditioning and similar systems is the most common mode of Legionnaires' disease transmission. The breakdown of the name of this disease shows that the Legionella refers to the legionnaires infected at the Philadelphia convention.

Certain health conditions widely observed in general public relate to skin diseases as a result of exposure to various exogenous agents. For instance, fairskinned, blue-eyed persons are prone to experience dry, wrinkled skin if they are exposed by occupation or sport to sunshine for prolonged periods and over many years. This skin condition is called golfer's skin and is also known as sailor's skin or farmer's skin. Another metaphor which permeates the field of forensic medicine relates to swelling of the skin tissue as a result of being immersed in water. These changes are referred to as washerwoman's changes or washerwoman syndrome in which the skin absorbs a great amount of water. This triggers skin proteins to increase in length followed by enlargement of the skin being folded up and wrinkled. People engaged in sporting activities may also experience skin conditions one of which is widely known as athlete's foot. This is a fungal infection of the skin between the toes and on the plantar surface of the foot which is commonly seen in athletes since the bacteria causing this skin condition mostly survives in dark, moist and warm environments usually around the swimming pools, bathrooms and locker rooms used by athletes. Reaction to flour, yeast, or other substances may cause a skin disease called baker's eczema which describes an allergic eruption on the hands and arms. It mostly occurs among bakers, though can well be observed in people not involved in baking. It can also happen due to the grain itch mite leading the disease to be also known as baker's itch. Skin conditions can occur not only due to a certain reaction to a particular agent but also due to some insects, for example, body lice. It can inhabit the skin tissue and cause pigmentation or discoloration if the skin has long been exposed to uncleanliness as a result of not maintaining proper hygiene. This skin condition is named 
vagabond's disease or vagrant's disease and is mostly seen in people who have an allergic reaction to louse bites.

Among musculoskeletal disorders numerous descriptions of fractures or malformations of upper and lower limbs can be found. One of them is called clay shoveler's fracture which is a fracture through the spinous process of a lower cervical vertebra or upper thoracic vertebrae. The etymology of the disease dates back to 1930s when men digging deep ditches in Australia tossed clay ten, twelve or even fifteen feet above their heads using long-handled shovels. This sticky clay didn't separate from the shovel and sticking to the instrument it added greater weight and posed hazard to the health of the worker. The clinical picture was as follows: sudden pain between the shoulders and then inability to continue the work. Hence, the term started to be widely applied in medicine and currently is also used with reference to similar fractures among workers engaged in shoveling other materials or employed in occupations which require lifting weight (with upper extremities stretched) and throwing it above over a certain distance (Hall, Perth \& Australia 1940). Another condition is connected with the fracture of the neck of a metacarpal bone in the hand. Typically, these are the metacarpal bones which connect the bones in the fingers to the wrist. The metaphor which is used to name this fracture is boxer's fracture. People are likely to sustain such fractures when punching an object or mechanism. Consequently, the name derives from this specific activity of punching or striking an immovable or hard object (for example, a wall) with unprotected fist. Hence, any metacarpal fracture is referred to as boxer's fracture by most clinicians and pathologists (WebMD).

People are likely to sustain injuries in the lower extremities as well. One of such injuries is called dancer's fracture which is an avulsion fracture caused by twisting injury to the ankle and foot. In this case a small fragment of bone is pulled away from the rest of the bone by a strong ligament (O’Malley, Hamilton \& Munyak 1996). Typically, this is a break of the long bone on the outside of the foot. The name may derive from the widespread perception that dancers may be prone to numerous fractures and injuries of foot, ankle and feet bones due to the dancing practices and performances.

Another metaphor denoting abnormalities connected with feet and anatomical parts of the feet is called dancer's heel. It describes a bony formation at the back of the ankle. This affects the posterior of the ankle and prevents from performing certain movements (Midwest Orthopaedics at Rush). Another condition affecting the foot is known as dancer's foot malformation which refers to a vigorous 
posteromedial contraction of the left ventricle coupled with convexity anteriorly sometimes resulting from poor contraction of the opposing anterior wall. Resembling a ballerina's foot this condition is also called ballerina foot. Repetitive activities of running, jumping, climbing, or kicking can also cause a condition known as jumper knee which describes a patellar or quadriceps tendonitis in feet. Some other conditions related to lower extremities are known as a rider's leg which describes a strain of the adductor muscles of the thigh; and a tennis leg which is a rupture of the gastrocnemius muscle at the musculotendinous junction, resulting from forcible contractions of the calf muscles. The latter is often seen in tennis players due to frequent quick stopping and starting movements.

Certain diseases are associated with the position or stance of human bodies. In particular, the disease called ballerina's pose is a type of cerebral palsy characterized by congenital spastic paralysis of the upper and lower extremities. In children it is described as a neurological disorder due to the impairment of the brain. In this case both the arms and legs are abnormally stiff; limbs are in a vertical position with the child's head dropped to the chest. This clinical picture forms a ballerina's pose. This condition was first observed by Dr. William John Little (1810 - 1894) who was himself suffering from a certain congenital deformity afflicting his left foot (Pearce 1988). In forensic medicine the metaphor pugilistic attitude or pugilistic stance describes a "defensive" position likened to the posture adopted by pugilists-boxers found in severely burned bodies. It is characterized by flexion of elbows, knees, hip, and neck, and clenching of hand into a fist. Another position called fencing position or fencing response is a peculiar position of the upper extremities, namely, a position assumed by the arms following a concussion of head and injured hemispheres of the brain. This condition resembles the position taken to initiate fencing in which one arm is extended and the other is raised.

Certain target organs may be affected as a result of various causative agents. Thus, people may be diagnosed with what doctors call a cobbler's chest. This is a congenital deformity of the anterior wall of the chest and produces a distinctly sunken chest seen in cobblers due to sitting in a certain position over a continued period. The movements of the head of a human body may as well bear abnormalities one of which is widely known as bishop's nod. This is a rhythmic bobbing or nodding of the head in synchrony with the heartbeat in aortic regurgitation and aortic aneurysm.

Hands can manifest signs of medical conditions one of which is likened to the position of the obstetrician's hand when examining the female genitals. It is 
therefore called obstetrician's hand or hand of the obstetrician. This condition is associated with tetany and is characterized with extension of the hand at the metacarpophalangeal and interphalangeal joints, and adduction of the thumb. In other words, the hand contracts and assumes cramped posture, flexed at the wrist with fingers at the metacarpophalangeal joints and extended at the interphalangeal joints; meanwhile the thumb is strongly flexed against the palm.

Ear tissue can be diagnosed with certain conditions one of which is identified as boxer's ear in which thickening and induration of the auricle is observed with distortion of its contours. An infection to the outer ear canal, which runs from the eardrum to the outside of the head is known as swimmer's ear. This is an inflammation of the external auditory canal and is caused by bacteria commonly found in water and soil. People usually experience swimmer's ear when water remains in ears after swimming since this creates the most beneficial moist environment triggering bacterial growth. One more metaphor characterizes a reddish-brown bulge involving the tip of the nose. This is a condition known as clown nose which reminds of the fake red nose clowns usually wear during their performances (Colletti et al 2014). Another condition with the nose tissue is metaphorically named toper's nose which describes enlargement (hypertrophy) of the nose. Increased vascularity of the nose skin and follicular dilation is observed followed by multiple red-coloured bumps on the nose. This condition is said to be associated with excessive consumption of alcoholic beverages and is also known as rum nose, rum-blossom or brandy nose. Alcohol consumption also impacts the caution measures exercised by people employed as gardeners. They are said to suffer from alcoholic rose gardener syndrome since they show less concern for caution measures and infections and to the skin abrasions. Such condition is commonly seen among alcoholics working as gardeners who have increased skin abrasions, and the metaphor alcoholic rose gardener syndrome is used to verbalize chronic mycosis and the above mentioned behaviour among them.

This list of metaphors can be characterized as comprising multiple expressions. However, this paper is not aimed at a comprehensive study of metaphors in medical discourse since that would require a lot of time and multifaceted medical literature. It should, nevertheless, be mentioned, that the listed metaphors succinctly communicate disease configurations and allow doctors to explain a particular clinical condition in a time-efficient manner and help to make the clinical picture of a disease easily recognizable based on associations of notions from different realms of knowledge. 


\section{Conclusion}

Given the statements above, it can be concluded that the metaphor facilitates the understanding of certain specialty-specific signs. In particular, it fosters clarity and saves time in communicating the intended idea in a more economic manner. Nowadays medical literature is replete with papers and research on specialtyspecific signs and descriptions of certain diseases and disorders which are quite frequently verbalized through metaphors. In such cases the metaphor serves as a cognitive device since it is accurate in the description of signs, causative agent and the outline of the disease. In addition, the usage of the metaphor justifies certain patterns of agenda doctors follow: they are precise and unambiguous and allow establishing a differential diagnosis thus helping to quickly proceed to the prevention and treatment of various diseases and pathologies which showcase specialty-specific signs.

\section{References:}

1. American Lung Association, Lung Health \& Diseases, Pneumoconiosis. Available at: $<$ http://www.lung.org/lung-health-and-diseases/lung-diseaselookup/pneumoconiosis/> [Accessed June 2016].

2. Avetisyan, A.G. (2007) Latineren-angleren-ruseren-hayeren bzhshkakan bararan. Yerevani M. Heratsu anvan petakan bzhshkakan hamalsaran. Yerevan: Heghinakayin hratarakutyun.

3. BONES. Foot and Ankle Injuries in Dancers - Midwest Orthopaedics at Rush. Available at: <http://www.rushortho.com/dancer-foot-ankle-injuries.cfm> [Accessed August 2016].

4. Broyard, A. (1992) Intoxicated by My Illness: and Other Writings on Life and Death. New York: C. Potter.

5. Centers for Disease Control and Prevention. Available at: $<$ http://www.cdc.gov/ $>$ [Accessed July 2016].

6. Colletti, G.; Allevi, F.; Moneghini, L.; \& Palvarini, M. (2014) Clown Nose: A Case of Disfiguring Nodular Squamous Cell Carcinoma of the Face. Case Reports, 2014 (Jan30/2). doi: 10.1136/bcr-2013-200471.

7. Davis, F.A. (2016) Taber's Quick Reference for Rehabilitation Professionals. Publisher: F.A. Davis.

8. Gibbs, R.W. (1994) The Poetics of Mind: Figurative Thought, Language, and Understanding. Cambridge: CUP. 
9. Holton, G.J. (1998) The Advancement of Science, and Its Burdens: With a New Introduction. Cambridge, MA: Harvard University Press.

10. Lakoff, G.; Johnson, M. (2003) Metaphors We Live By. London: The University of Chicago Press.

11. (2007) Legionella and the Prevention of Legionellosis. // World Health Organization. / Ed. by J. Bartram, Y. Chartier, J.V Lee, K. Pond and S. Surman-Lee. WHO Library Cataloguing-in-Publication Data. Available at: $<\mathrm{http}$ ://www.who.int/water_sanitation_health/emerging/legionella.pdf $>$ [Accessed August 2016].

12. Legionellosis, Fact Sheet. / World Health Organization. Available at: $<\mathrm{http}$ ://www.who.int/mediacentre/factsheets/fs285/en/> [Accessed July 2016].

13. Locke, J. (2007) An Essay Concerning Human Understanding. Book III: Words. Available at: <http://www.earlymoderntexts.com/pdf/lockess3.pdf $>$ [Accessed September 2016].

14. McKellar Hall, R.D. (1940) Clay-Shoveler's Fracture. Archive, 22(1), pp. 6375. Available at: <http://jbjs.org/content/22/1/63> [Accessed July 2016].

15. Mayo Clinic, Diseases and Conditions, Legionnaires' Disease. Available at: $<\mathrm{http}$ ://www.mayoclinic.org/diseases-conditions/legionnairesdisease/basics/definition/ con-20028867> [Accessed July 2016].

16. Nerkin hivandutyunneri propedevtika. (2011) Usumnakan dzernark. / Khmb. H.S. Sisakyan, A.A. Ayvazyan. Yerevan: Yerevani M. Heratsu anvan petakan bzhshkakan hamalsarani hratarak.

17. O'Malley, M.J.; Hamilton, W.G. \& Munyak, J. (1996) Fractures of the Distal Shaft of the Fifth Metatarsal: Dancer's Fracture. // The American Journal of Sports Medicine, 24(2), pp. 240-243. doi:10.1177/036354659602400223.

18. Oxford Dictionaries. Available at: <http:/www.oxforddictionaries.com/ definition/english/-philia?q=philia $>$ [Accessed July 2016].

19. Richards, I.A. (1936) The Philosophy of Rhetoric. Oxford: OUP.

20. Segen, J.C. (1992) The Dictionary of Modern Medicine. Carnforth, Lancs, UK: Parthenon Pub. Group.

21. Skinner, H.A. (1949) The Origin of Medical Terms. Baltimore: Williams \& Wilkins Co

22. Stedman's Online Medical Dictionary. Available at: $<$ http://stedmansonline.com/>, [Accessed September 2016].

23. Unschuld, P.U. (1998) Forgotten Traditions of Ancient Chinese Medicine. Brookline, MA, USA: Paradigm Publications. 
24. Vickers, B. (1970) Classical Rhetoric in English Poetry. London: Macmillan and Co.

25. Tufenkjian, K., \& Lüders, H.O. (2012) Seizure Semiology: Its Value and Limitations in Localizing the Epileptogenic Zone. // Journal of Clinical Neurology (Seoul, Korea), 8(4): pp. 243-250. Available at: <http://doi.org/ 10.3988/jcn.2012.8.4.243> [Accessed July 2016].

26. Pearce, J. (1988) Little's Disease. // Journal of Neurology, Neurosurgery, and Psychiatry, 51(12), p.1593. Available at:

$<$ https://www.ncbi.nlm.nih.gov/pmc/articles/PMC1032783> [Accessed July 2016].

27. WebMD. Available at: <http://www.webmd.com/a-to-z-guides/boxers-fracture? print $=$ true $>$ [Accessed July 2016].

28. World Health Organization. Available at: <http://www.who.int/water sanitation_health/emerging/legionella.pdf $>$ [Accessed July 2016].

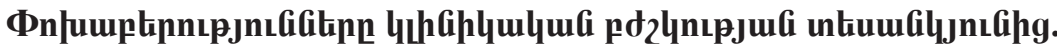

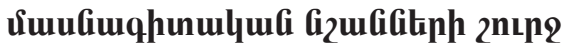

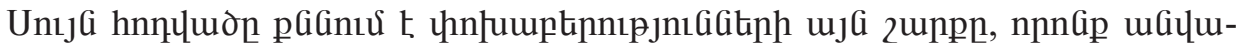

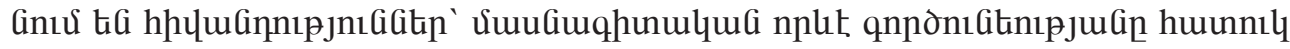

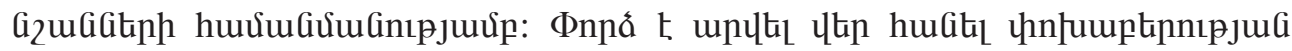

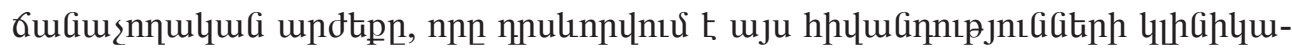

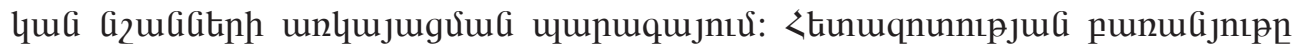

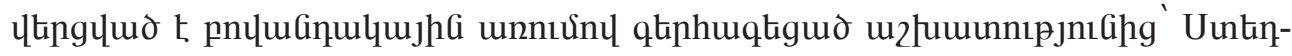

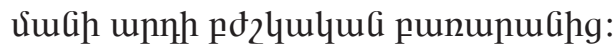

